\title{
Reflexiones ante la transposición de la Directiva 2001/29/CE, relativa a los derechos de autor en la sociedad de la información
}

Núria Gallart

Jefe de proyectos del Servicio de Bibliotecas de la Universidad Autónoma de Barcelona

Miembro del Grupo Bibliotecas y Propiedad Intelectual de FESABID

\section{Resumen:}

Tras la aprobación de la Directiva 200 I/29/CE, del Parlamento Europeo y del Consejo, de 22 de mayo de 200 I, relativa a la armonización de determinados aspectos de los derechos de autor y derechos afines a los derechos de autor en la sociedad de la información, se ha abierto el período de transposición a las legislaciones nacionales de los distintos Estados miembros de la Unión Europea.

Este artículo intenta exponer los puntos de interés desde la perspectiva de las bibliotecas y centros culturales de servicio público, con especial hincapié en el significado de las excepciones y limitaciones, que afectan al entorno digital, previstas por la Directiva.

\section{Palabras clave:}

Derechos de autor / Bibliotecas / Directiva 2001/29/CE

\section{Objetivos de la Directiva}

La publicación de la Directiva 200 //29/CE, del Parlamento Europeo y del Consejo, de 22 de mayo de 200I, relativa a la armonización de determinados aspectos de los derechos de autor $y$ derechos afines a los derechos de autor en la sociedad de la información (DOCE LI67/I0, 22-6-200 I) marca el final de largos debates y numerosas revisiones de un texto legislativo cuyos objetivos principales pueden ser enunciados de la siguiente manera:

I. Dar seguridad jurídica a los autores, editores y otros titulares de derechos de propiedad intelectual en relación con el respeto de dicha propiedad en el entorno digital

2. Incorporar a la legislación de propiedad intelectual la protección de las medidas tecnológicas eficaces que los titulares de derechos introduzcan con el fin de proteger dicha propiedad y de incluir la información sobre sus derechos.
3. Armonizar, aunque sea parcialmente, las disparidades existentes entre las distintas legislaciones nacionales de los Estados miembros de la Unión Europea a fin de evitar en lo posible las diferencias que afectan al correcto funcionamiento del mercado interior.

Los dos primeros objetivos coinciden plenamente con las líneas de desarrollo marcadas por el texto del Tratado de la OMPI sobre Derecho de Autor que se aprobó en diciembre de 1996 y va a entrar en vigor el 6 de marzo de 2002. Al igual que el Tratado de la OMPI sobre interpretación o ejecución y fonogramas próximo a alcanzar el mínimo de treinta Estados adheridos que se requiere para poder entrar en vigor.

Se consideró imprescindible la declaración explícita del derecho de autores, editores y otros titulares de derechos de autor y derechos afines, a la explotación de sus obras en el entorno digital y virtual para eliminar ambigüedades que impedían un rápido desarrollo de contenidos en la red así como la digitalización de información preexistente.

Además se deseaba promover nuevas formas de explotación de los contenidos, aprovechando al máximo las posibilidades del comercio electrónico, el cual requiere para su desarrollo medidas de seguridad tecnológicas que garanticen su normal funcionamiento y un marco jurídico internacional que obligue al respeto de las mismas.

El éxito obtenido con respecto al tercer objetivo, la armonización, es discutible por cuanto se mantienen las disparidades existentes en los diferentes Estados miembros en relación a las excepciones y limitaciones tradicionales para las obras en un soporte tangible como el papel. Sin embargo, se prohíbe la introducción de nuevas excepciones y se limita estrictamente la posibilidad de crear nuevas diferencias, restringiendo incluso su ámbito de aplicación en el caso de las obras en formato digital.

\section{Aspectos destacables}

I. Se establece claramente el derecho exclusivo de los autores y otros titulares a autorizar o prohibir cualquier acto de reproducción, de comunicación al público y de distribución de sus obras (artículos 2 a 4 de la Directiva).

2. Se mencionan las excepciones y limitaciones que los Estados podrán introducir en sus legislaciones. La lista de excepciones y limitaciones es exhaustiva y de 
aplicación voluntaria (artículo 5). Sólo es obligatoria la excepción que permite la realización de reproducciones técnicas transitorias en el entorno digital (artículo 5.1).

3. Se establece la obligatoriedad de la protección de las medidas tecnológicas de protección de los derechos de autor, con la persecución de la fabricación, importación, distribución, venta, alquiler, publicidad o posesión con finalidades comerciales de cualquier dispositivo, producto o servicio destinado a eludir aquellas medidas (artículo 6).

4. Deberá asimismo establecerse protección contra la supresión o alteración de la información necesaria para la gestión electrónica de los derechos de autor (artículo 7).

\section{Derecho de poner a disposición del público prestaciones protegidas}

La Directiva 2001/29/CE no se ocupa de los derechos morales de los autores (considerando 19) sino únicamente de los derechos de explotación y, ello, sin perjuicio de no afectar la directivas anteriores en vigor relativas al préstamo y alquiler, a la duración de los derechos de autor, a las bases de datos, a los programas de ordenador y a las retransmisiones de radio y televisión.

A los tradicionales derechos de explotación consistentes en la reproducción, la comunicación al público y la distribución de ejemplares añade el concepto de puesta a disposición del público y lo incluye entre las acepciones del derecho de comunicación. Con ello se cubren los actos de acceso de cualquier persona a las obras desde el lugar y en el momento que ella elija; es decir, el acceso a contenidos a través de Internet.

\section{Las excepciones y limitaciones}

En el artículo 5 de la Directiva se halla una lista exhaustiva de excepciones y limitaciones con dos tipos claramente diferenciados. Hay una única excepción obligatoria al derecho de reproducción con la cual se cubre la necesidad de permitir copias técnicas realizadas por prestadores de servicios de información y comunicaciones, con el fin de agilizar y mejorar la rapidez de las redes.

Hay a continuación dos listas exhaustivas de excepciones o limitaciones que los Estados miembros pueden aplicar a sus legislaciones nacionales: la primera, referente al derecho de reproducción exclusivamente; y la segunda, a los derechos de reproducción y de comunicación pública combinados.

Debe ofrecerse a los Estados miembros la posibilidad de establecer determinadas excepciones o limitaciones en casos tales como aquellos en que se persiga una finalidad educativa o científica, en beneficio de organismos públicos, tales como bibliotecas y archivos, con fi- nes de información periodística, para citas, para uso por personas minusválidas, para usos relacionados con la seguridad pública y para uso en procedimientos administrativos y judiciales (considerando 34).

La filosofía del establecimiento de una lista amplia ha sido la de permitir el mantenimiento de las excepciones y limitaciones vigentes en cada país y que en el entorno analógico -léase, impreso o en otros soportes físicos- no causaban problemas al mercado interior y fijar las posibles excepciones y limitaciones que pueden aplicarse al entorno digital (considerando 32).

Las bibliotecas y otros organismos culturales son mencionadas en dos excepciones posibles:

Excepción al derecho de reproducción:

en relación con actos de reproducción efectuados por bibliotecas, centros de enseñanza o museos accesibles al público, o por archivos, que no tengan intención de obtener un beneficio económico o comercial directo o indirecto (artículo $5.2 \mathrm{c}$ ).

Excepción a los derechos de reproducción y de comunicación:

cuando el uso consista en la comunicación a personas concretas del público o la puesta a su disposición, a efectos de investigación o de estudio personal, a través de terminales especializados instalados en los locales de los establecimientos mencionados en la letra c) del apartado 2, de obras y prestaciones que figuran en sus colecciones y que no son objeto de condiciones de adquisición o de licencia (artículo 5.3 n).

Con estas dos excepciones se pretende satisfacer las necesidades de reproducción analógica y digital realizada por centros culturales públicos con la finalidad de facilitar la investigación y posibilitar la conservación del patrimonio. Sin embargo, se hace prevalecer las condiciones de contratos y licencias en caso de entrar en conflicto con la excepción del artículo 5.3 n.

Ambas excepciones deberían transponerse a la legislación española para poder asegurar un funcionamiento eficaz de las instituciones culturales de nuestro país, al mismo tiempo que es necesario que se mantenga la vigente excepción respecto a los préstamos realizados por estos centros, excepción que la Directiva permite mantener sin problema alguno (considerando 40).

\section{Copia privada}

La excepción que puede permitir la copia privada, queda estrictamente limitada a la realizada por una persona física para uso privado y sin fines directa o indirectamente comerciales. Los titulares de los derechos deberán recibir una compensación equitativa por este concepto pero teniendo en cuenta si se 
aplican o no a la obra o prestación de que se trate las medidas tecnológicas de protección.

Las entidades de gestión colectiva de derechos de autor ya están adaptando sus estatutos al entorno digital y pretenden cobrar cánones por materiales que hasta ahora eran considerados del mundo de la informática y no de los contenidos, como por ejemplo el CD-R. A la unificación de formatos producida por la digitalización que puede conllevar el reclamo de múltiples entidades de gestión por diferentes conceptos para un único soporte, habrá que añadir la implementación de las medidas tecnológicas de protección que puede llegar a evitar el disfrute de la excepción a pesar del pago de dobles o triples cánones.

Habrá que seguir atentamente el desarrollo de los acontecimientos y los resultados de la aplicación de la Directiva en este ámbito para corregir posibles disfunciones.

\section{Docencia y citas}

En la Directiva aparece una primera excepción a la reproducción y a la comunicación para usos de ilustración con fines educativos o de investigación científica, siempre que la finalidad no sea comercial y se indique la fuente. Y una segunda excepción posible para citas y reseñas.

En la legislación española vigente sólo se menciona la excepción para citas y reseñas y aún constreñida al ámbito docente e investigador. Sería recomendable transponer las dos excepciones de la Directiva por separado para su mejor entendimiento y uso.

\section{Protección de medidas tecnológicas e información para la gestión de derechos}

La Directiva, acorde con el Tratado de la OMPI sobre Derecho de Autor, introduce en su texto la protección de las medidas tecnológicas que han de proteger a su vez los contenidos o las prestaciones de servicios de la sociedad de la información.
La protección de las medidas tecnológicas eficaces es obligatoria para los Estados miembros y debe consistir en la persecución de la fabricación, importación, distribución, venta, alquiler, publicidad para la venta o el alquiler, o posesión con fines comerciales, de cualquier dispositivo, producto o componente o la prestación de servicios que tengan por finalidad eludir una protección.

Sólo si los titulares de derechos, mediante la aplicación de medidas tecnológicas y por falta de voluntad propia o de llegar a acuerdos estuvieran impidiendo el disfrute de algunas excepciones presentes en la legislación nacional, los Estados miembros deberían tomar las medidas oportunas para forzar a los titulares a facilitar dicho disfrute. No queda nada claro cómo ni en qué momento el Estado puede llegar a sentirse en la obligación de intervenir.

Del mismo modo se establece la protección de la información sobre la gestión de derechos, ya que es un pilar fundamental para la puesta en marcha del comercio electrónico.

\section{Conclusiones}

El proceso de transposición de la Directiva 200 I/29/CE relativa a la armonización de derechos de autor y derechos afines en la sociedad de la información está abierto y debería concluir antes del 22 de diciembre de 2002.

Los resultados de dicha transposición configurarán el marco en el que deberemos trabajar los profesionales del sector cultural y de gestión de la información durante los próximos años y condicionará los servicios que podamos ofrecer a nuestros usuarios así como su coste final.

Desde el Grupo BPI de FESABID consideramos de la mayor importancia que los profesionales del sector nos impliquemos en el proceso y hagamos oír nuestra voz públicamente para exponer las necesidades respecto a normativas que permitan el funcionamiento eficaz de nuestros servicios, así como la entrada y la participación efectiva de nuestros centros en la sociedad de la información.

\section{Referencias bibliográficas}

Tratado de la OMPI sobre Derecho de Autor. (WCT, 20- 12 1996). Entrará en vigor el 6 de marzo de 2002. [En línea en: http://www.wipo.int/treaties/ip/copyright/index-es.html Consulta: 3।-I-2002]

Directiva 2001/29/CE, del parlamento Europeo y del Consejo, de 22 de mayo de 2001 , relativa a la armonización de determinados aspectos de los derechos de autor y derechos afines a los derechos de autor en la sociedad de la información. (DOCE L 167//0, 22-6-200I) [En línea en: http://europa.eu.int/eurlex/es/lif/dat/200 I/es_30 IL0029.html Consulta: 3 I - I-2002]

Real Decreto Legislativo I//996, de 12 de abril, por el que se aprueba el texto refundido de la Ley de Propiedad Intelectual, regularizando, aclarando y armonizando las disposiciones legales vigentes sobre la materia. (BOE 22-4-1996) [En línea en: http://www.mcu.es/Propiedad_Intelectual/05_legislac.htm Consulta: 31-I-2002]

PATRICIA RIERA BARSALLO. "Los derechos de autor y sus límites: un equilibrio necesario". En: PH. Boletín del IAPH, n 33, diciembre 2000, pp. 200-204.

VINCENT GRYNBAUM. "Le droit de reproduction à I'heure de la société de l'information". En: Juriscom.net 13-12-200।. [En línea en: http://www.juriscom.net/pro/2/da200 I I I 3.pdf Consulta: 31 I-2002]

Grupo BPI de FESABID

Web oficial: http://www.fesabid.org/

Web de recursos: http://www.bib.uab.es/project/cas/piadrO.htm 